GRADIATION\&APPLICATIONS

ISSN 2466-4294 (online) | rad-journal.org

Vol. 2 | Issue 1 | pp. $26-30$

doi: 10.21175/RadJ.2017.01.006

Original research paper

\title{
THE MENTAL FORAMEN POSITION IN RELATION TO THE RADIOGRAPHIC APEX OF THE MANDIBULAR SECOND PREMOLAR*
}

\author{
Jelena Popović ${ }^{{ }^{* *}}$, Marija Daković Bjelaković ${ }^{2}$ \\ Jovanka Gašić1, Milan Spasić3, Marija Nikolić1, Radomir Barac1 \\ ${ }^{1}$ Department of Restorative Dentistry and Endodontics, Clinic of Dentistry, Faculty of Medicine, University of Niš, \\ Serbia \\ ${ }^{2}$ Department of Anatomy, Faculty of Medicine, University of Niš, Serbia \\ 3Department of Oral Surgery, Clinic of Dentistry, Faculty of Medicine, University of Nišs, Serbia
}

\begin{abstract}
The identification of the mental foramen is important for both diagnostic and clinical procedures. The knowledge about its accurate location is significant in reducing complications that may occur during surgical and endodontic treatments involving the mental area. The purpose of this study was to determine the position of mental foramen in relation to the radiographic apex of the mandibular second premolar on panoramic radiographs. Two hundred digital panoramic radiographs were analyzed in this study. Horizontal and vertical position of the mental foramen was determined in relation to the two reference lines which passed through the apex of the mandibular second premolar. The possible positions were: mesial below, mesial intersecting, mesial above, intersecting below, centered, intersecting above, distal below, distal intersecting and distal above. Fifty percent of the panoramic radiographs showed that the mental foramen position was mesial and below the radiographic apex of the second premolar. Mesial and intersecting position was observed in $21 \%$ of the radiographs, centered in $13 \%$, intersecting and below in $8 \%$, distal and below in 6\%, while $2 \%$ of the radiographs showed distal and intersecting position of the mental foramen. No statistically significant differences in the position and the symmetry of the mental foramen were observed in relation to the gender and the side of the mandible. The most common position of the mental foramen was mesial and below the radiographic apex of the mandibular second premolar. For an accurate assessment of the location of the mental foramen, a preoperative radiological study with a panoramic radiograph is necessary.
\end{abstract}

Key words: Mental foramen, mandible, second premolar, panoramic radiograph

\section{INTRODUCTION}

The mental foramen is an important anatomical structure which represents the termination of the mental canal, and is located on the lateral surface of the mandible. The mental nerve passes through the mental foramen and supplies sensory innervation and nutrition to the soft tissues of the chin, lower lip and gingiva on the ipsilateral side of the mandible [1]. Visualization of the mental foramen on periapical radiographs may be difficult because its position is usually below the edge of the film. Panoramic radiographs provide the ability to view the entire body of mandible and allow more accurate localization of mental foramen in both horizontal and vertical dimension [2]. Studies reporting the radiographic position of the mental foramen have been variable and their results were different. Individual variation could place the mental foramen anywhere from the apex of the canine to the apex of the mesial root of the mandibular first molar [3]. The identification of the mental foramen location is important for both diagnostic and clinical procedures. In the field of endodontics, radiographic appearance of the mental foramen may result in misdiagnosis of radiolucent periapical lesion in the area of mandibular premolar teeth [4]. Clinically, the mental nerve could be traumatized during surgical procedures and overfilling of the root canals resulting in paresthesia and anesthesia [5].

The purpose of this study was to determine the position of mental foramen in relation to the radiographic apex of the mandibular second premolar on panoramic radiographs.

\section{MATERIAL AND METHOD}

Two hundred digital panoramic radiographs of the patients from the Clinic of Dentistry in Niš were analyzed in this study. All of the radiographs were taken using a digital Orthopantomograph (Carestream

\footnotetext{
* The paper was presented at the Fourth International Conference on Radiation and Applications in Various Fields of Research (RAD 2016), Niš, Serbia, 2016.

jelenadp@gmail.com
} 
CS 9000), in position where the patients head was tilted around $5^{\circ}$ downward in relation to the Frankfort plane. The study included the cases with all teeth present from mandibular central incisor to the first molar on the both sides of the mandible and with no development anomalies of the jaws.

The radiographs were free from radiolucent or radiopaque lesions in the lower arch and showed no exposure or processing artefacts. The youngest patient was 18-years-old and the oldest 62 years with a mean of 31 years (108 males and 92 females).

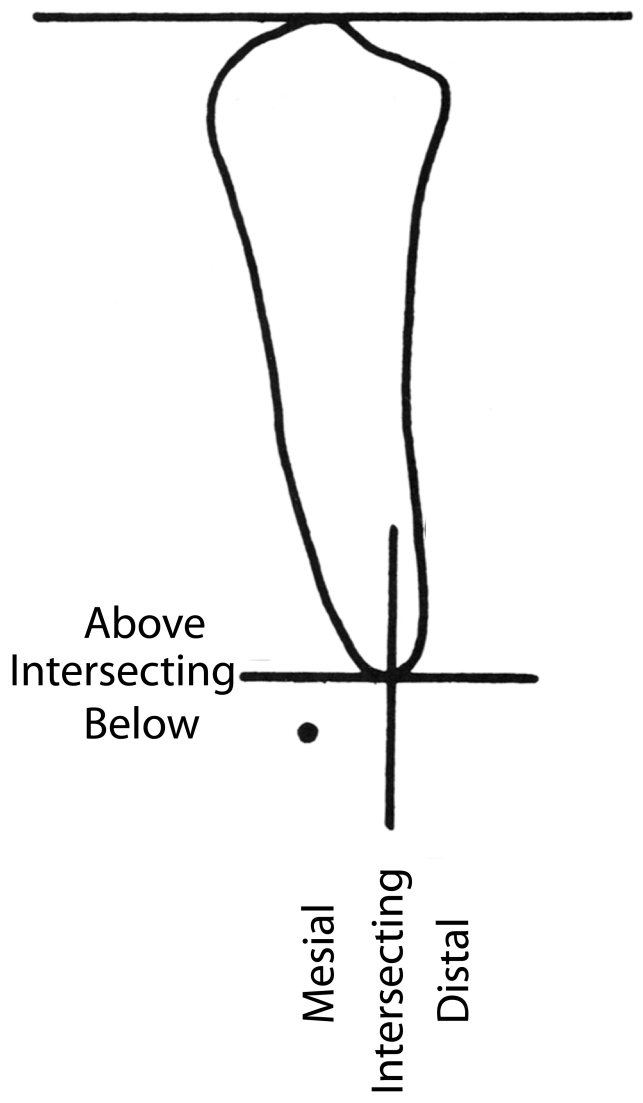

Figure 1. Horizontal and vertical line at the radiographic apex of the left second premolar
Each radiograph was carefully analyzed in order to observe the presence and accurate location of the left and right mental foramen. According to Phillips et al. [2], horizontal and vertical position of the mental foramen was determined in relation to the two reference lines that passed through the radiographic apex of the tooth (Figure 1).

A horizontal line was parallel to the occlusal line at the radiographic apex of the second premolar, while the vertical line was perpendicular to the horizontal line at the apex of the tooth. Horizontal position was recorded as mesial, intersecting or distal to the vertical line, while vertical position was recorded as above, intersecting or below the horizontal line. The results were analyzed in relation to the gender and the side of the mandible.

Statistical analysis was carried out using $\chi^{2}$ test. A p value less than 0.05 was considered to be statistically significant.

\section{RESULTS}

Seventy one percent of the cases showed the location of the mental foramen between the first and the second premolar. The most common position of the mental foramen for both genders and both sides was mesial and below the radiographic apex of the second premolar (50\%) $227.25 \%$ for males and $22.75 \%$ for females; $26 \%$ for the left side and $24 \%$ for the right side) (Figure 2). Mesial and intersecting position was observed in $21 \%$ of the radiographs $(9.5 \%$ for males and $11.5 \%$ for females; $10 \%$ for the left side and $11 \%$ for the right side), centered in $13 \%(7.25 \%$ for males and $5.75 \%$ for females; $5 \%$ for the left side and $8 \%$ for the right side), intersecting and below in $8 \%$ ( $5 \%$ for males and $3 \%$ for females; $5 \%$ for the left side and $3 \%$ for the right side), distal and below in 6\% (3.5\% for males and $2.5 \%$ for females; $3 \%$ for the left side and $3 \%$ for the right side), while $2 \%$ of the radiographs showed distal and intersecting position of the mental foramen $(1.5 \%$ for males and $0.5 \%$ for females; $1 \%$ for the left side and $1 \%$ for the right side) in relation to the radiographic apex of the mandibular second premolar (Table 1). No statistically significant difference was observed in position of the mental foramen between males and females ( $>0.05$ ) (Table 2) and between left and the right side $(\mathrm{p}>0.05)$ (Table 3$)$.

Table 1. The position of the mental foramen in relation to the gender and side

\begin{tabular}{|c|c|c|c|c|c|c|}
\hline \multirow{2}{*}{\multicolumn{2}{|c|}{ Position }} & \multicolumn{2}{|c|}{$\begin{array}{c}\text { Male (108) } \\
(n=216)\end{array}$} & \multicolumn{2}{|c|}{$\begin{array}{c}\text { Female (92) } \\
(n=184)\end{array}$} & \multirow{3}{*}{$\begin{array}{c}\begin{array}{c}\text { Total }(200) \\
(n=400)\end{array} \\
n(\%) \\
200(50)\end{array}$} \\
\hline & & Left, $n$ (\%) & Right, $n$ (\%) & Left, $n(\%)$ & Right, $n$ (\%) & \\
\hline \multirow{3}{*}{ Mesial } & Below & $52(13)$ & $57(14.25)$ & $52(13)$ & $39(9.75)$ & \\
\hline & Intersecting & $20(5)$ & $18(4.5)$ & $20(5)$ & $26(6.5)$ & $84(21)$ \\
\hline & Above & - & $\begin{array}{l}- \\
-\end{array}$ & - & - & - \\
\hline \multirow{3}{*}{ Intersecting } & Below & $14(3.5)$ & $6(1.5)$ & $6(1.5)$ & $6(1.5)$ & $32(8)$ \\
\hline & Centered & $12(3)$ & $17(4.25)$ & $8(2)$ & $15(3.75)$ & $52(13)$ \\
\hline & Above & - & - & - & - & - \\
\hline \multirow{3}{*}{ Distal } & Below & $6(1.5)$ & $8(2)$ & $6(1.5)$ & $4(1)$ & $24(6)$ \\
\hline & Intersecting & $4(1)$ & $2(0.5)$ & - & $2(0.5)$ & $8(2)$ \\
\hline & Above & - & - & - & - & - \\
\hline \multicolumn{2}{|c|}{ Total } & $108(27)$ & $108(27)$ & $92(23)$ & $92(23)$ & $400(100)$ \\
\hline
\end{tabular}




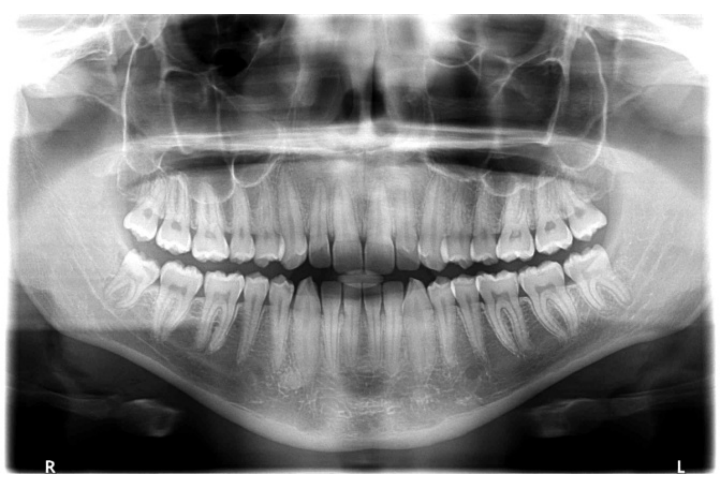

Figure 2. The most common position of the mental foramen (mesial and below)

Table 2. The position of the mental foramen in relation to the gender

\begin{tabular}{|l|l|c|c|}
\hline \multicolumn{2}{|c|}{} & \multicolumn{2}{c|}{ Total $(n=400)$} \\
\cline { 3 - 4 } \multicolumn{2}{|c|}{ Position } & $\begin{array}{c}\text { Male } \\
n(\%)\end{array}$ & $\begin{array}{c}\text { Female } \\
n(\%)\end{array}$ \\
\hline \multirow{4}{*}{ Mesial } & Below & $109(27.25)$ & $91(22.75)$ \\
\cline { 2 - 4 } & Intersecting & $38(9.5)$ & $46(11.5)$ \\
\cline { 2 - 4 } & Above & - & - \\
\hline \multirow{4}{*}{ Intersecting } & Below & $20(5)$ & $12(3)$ \\
\cline { 2 - 4 } & Centered & $29(7.25)$ & $23(5.75)$ \\
\cline { 2 - 4 } & Above & - & - \\
\hline \multirow{4}{*}{ Distal } & Below & $14(3.5)$ & $10(2.5)$ \\
\cline { 2 - 4 } & Intersecting & $6(1.5)$ & $2(0.5)$ \\
\cline { 2 - 4 } & Above & - & - \\
\hline
\end{tabular}

Table 3. The position of the mental foramen in relation to the side

\begin{tabular}{|l|l|c|c|}
\hline \multicolumn{2}{|c|}{ Position } & \multicolumn{2}{c|}{ Total $(n=400)$} \\
\cline { 3 - 4 } & $\begin{array}{c}\text { Left } \\
n(\%)\end{array}$ & $\begin{array}{c}\text { Right } \\
n(\%)\end{array}$ \\
\hline \multirow{4}{*}{ Mesial } & Below & $104(26)$ & $96(24)$ \\
\cline { 2 - 4 } & Intersecting & $40(10)$ & $44(11)$ \\
\cline { 2 - 4 } & Above & - & - \\
\hline \multirow{4}{*}{ Intersecting } & Below & $20(5)$ & $12(3)$ \\
\cline { 2 - 4 } & Centered & $20(5)$ & $32(8)$ \\
\cline { 2 - 4 } & Above & - & - \\
\hline \multirow{4}{*}{ Distal } & Below & $12(3)$ & $4(1)$ \\
\cline { 2 - 4 } & Intersecting & $4(1)$ & - \\
\cline { 2 - 4 } & Above & - & $4)$ \\
\hline
\end{tabular}

The mental foramina were symmetrically located in $74 \%$ of the cases (Table 4). No statistically significant differences were observed between males and females in symmetry and asymmetry of the mental foramen position ( $\mathrm{p}>0.05)$.

Table 4. The symmetry of the mental foramen in relation to the gender

\begin{tabular}{|c|c|c|c|}
\hline Gender & $\begin{array}{c}\text { Symmetrical } \\
n(\%)\end{array}$ & $\begin{array}{c}\text { Asymmertical } \\
n(\%)\end{array}$ & $\begin{array}{c}\text { Total } \\
n(\%)\end{array}$ \\
\hline Male & $76(38)$ & $32(16)$ & $108(54)$ \\
\hline Female & $72(36)$ & $20(10)$ & $92(46)$ \\
\hline Total & $148(74)$ & $52(26)$ & $200(100)$ \\
\hline
\end{tabular}

\section{DISCUSSION}

Many clinical procedures require an accurate knowledge of the location and orientation of the mental canal and its foramen [5]. Since there are no absolute anatomical landmarks for reference, the foramen cannot be clinically visualized or palpated [3]. From clinical point of view, local anesthesia for dental treatments and safety of surgical and endodontic treatments require knowledge about position of the mental foramen. It could also play role in interpreting anatomical landmarks in forensics [6].

Since the mental foramen is one of the most important landmarks of the mandible, determination of its location, shape, size and distance from other anatomic structures and adjacent roots has been subject of many studies [6]. Two different approaches to the study of mental foramina are available: evaluation and statistical analysis of panoramic radiographs of a large group of patients and experimental procedures carried out on dry skulls [7]. The studies of Philips et al. [3,5], Igbigbi et al. [8] and Singh et al. [9] used dry human mandibles for detection of mental foramen. These studies had advantage of having wire markers placed over the center of the foramen, so the visualization of each foramen was much easier. Other studies located the mental foramen on periapical and panoramic radiographs $[2,4,10]$. In the majority of cases where the foramen could not be seen, its position was actually below the edge of the periapical radiographic film. In these cases vertical radiographs could not be possible due to soft tissues on the floor of the mouth [3]. This study used panoramic radiographs in analyzing the position on mental foramen. The ability to view the entire body of the mandible on panoramic radiograph is a great help in locating the mental foramen due to ability to follow the course of the inferior alveolar and the mental canal which also aid the visualization of the mental foramen. The horizontal position of the mental foramen on the panoramic radiograph generally agrees with the position reported on periapical radiographs [2].

The results of this study showed that in most of cases, mental foramen was located mesial and below the radiographic apex of the second premolar. These results agree with the reports of Philips et al. [2,3,5] who found it between the apices of the two premolars in 63 to $70 \%$ of the cases. Similar results were obtained by Al-Shayyab et al. [11] and Babshet et al. [12] who reported that the most common location of the mental foramen was between the first and the second premolar.

According to Ngeow et al. [4] the most common position of the mental foramen, relative to the teeth in their study, was in line with the second premolar for both the right and left side. The second most common location was between the first and the second premolar. Singh et al. [9] also showed that the most common position of the mental foramen was below the apex of the second premolar. They have reported that accessory mental foramen was present in 8 percent on left side, and 5 percent on right side, while none of the mandibles presented bilateral accessory mental foramen. Chkoura and Wady [13] and Khojastepour et 
J. Popović et al., The Mental Foramen Position..., Rad. Applic., 2017, 2, 1, 26-30

al. [6] reported that the most common position of the mental foramen was below the apex of the second premolar followed by the position between the first and the second premolar. Philips et al. [2,3,5] have determined that the mental foramen was located directly below the crown of the second premolar in majority of examined dry human mandibles. Radiographic position was found mesial to the apex of this tooth ( $71 \%$ of the cases). One reason for this mesial shift may be due to the distal curvature of the root apex of this tooth. Their analysis of the panoramic radiographs showed the average position of the mental foramen $0.13 \mathrm{~mm}$ mesial and $3 \mathrm{~mm}$ below the radiographic apex of the second premolar.

Many studies have analyzed the mental foramen position in different population groups and showed that variations do exist $[8,14]$. Santini and Alayan [15] compared position of the mental foramen in three populations (Chinese, European and Indian) and found that it was in line with the second premolar for Chinese population and between the first and the second premolar for European and Indian population. The position between the first and the second premolar for Indian population was confirmed by Babshet et al. [12] and the same position was reported by Al-Shayyab et al. [11] for Iraqi population. Chokura and Wady [13] showed that the most common position of the foramen in Moroccan population was below the apex of the second premolar. The position below the second premolar was also reported by Khojastepour et al. [6] who have analyzed Iranian population. However, the studies also examined males and females and concluded that the location of the mental foramen is not gender-dependent $[1,16]$. The results of this study also showed that there was no statistically significant difference in position of the mental foramen between males and females and it was in accordance with the literature data $[6,11,12,13]$.

Overfilling of the root canals, near anatomical structures such the nerves are, may cause a different kinds of sensitive disturbances, which vary from anesthesia, paresthesia, dysestesia and hypoesthesia [10]. Berberoglu et al. [17] reported a case of four months prolonged anesthesia of the mental nerve caused by overextension of endodontic sealer near mental foramina. In planning of oral implants, an important aspect to consider is the localization of anatomical landmarks in the area of the potential implant since this determines its dimensions and the axes [18-20]. Implant placement in the mandibular premolar region is a complicated surgical procedure due to potential inadvertent complications of neurosensory alterations in the chin and lower lip that are likely occur if mental foramen is not properly identified and protected [6].

\section{CONCLUSION}

The most common position of the mental foramen was mesial and below the radiographic apex of the mandibular second premolar. For an accurate assessment of location of mental foramen a preoperative radiological study with panoramic radiograph is necessary.
Acknowledgement: This work has been supported by the grant No. 175102 of the Serbian Ministry of Science.

\section{REFERENCES}

1. V. Aher, P. Pillai, F. Mukram Ali, M. Mustafa, M. Ahire, A. Mudhol and M. Kadri, "Anatomical Position of Mental foramen: a Review," Global Journal of Medicine and Public Health, vol. 1, pp. 61-64, 2012.

2. J. L. Philips, R. N. Weller, and J. C. Kulild, "The mental foramen: Part III. Size and position panoramic radiographs," J. Endod., vol. 18, no. 8, pp. 383-386, Aug. 1992. DOI: 10.1016/Soo99-2399(06)81224-0

3. J. L. Philips, R. N. Weller, and J. C. Kulild, "The mental foramen: Part II. Radiographic position in relation to the mandibular second premolar," J. Endod., vol. 18, no. 6. pp. 271-274, Jun. 1992. DOI: 10.1016/Soo99-2399(06)80953-2

4. W. C. Ngeow and Y. Yuzawati, "The location of the mental foramen in a selected Malay population," $J$. Oral Sci., vol. 45, no. 3, pp. 171-175, 2003.

DOI: $10.2334 /$ josnusd.45.171 PMid: 14650583

5. J. L. Philips, R. N. Weller and J. C. Kulild, "The mental foramen: Part I. Size, orientation, and positional relationship to the mandibular second premolar," $J$. Endod., vol. 16, no. 5, pp. 221-223, May 1990. DOI: 10.1016/Soo99-2399(06)81674-2

6. L. Khojastepour, S. Mirbeigi, S. Mirhadi, A. Safaee, "Location of mental foramen in selected Iranian population: A CBCT assessment," Iran. Endod. J., vol. 10, pp. 117-121, 2015. PMid: 25834596 PMCid: PMC4372786

7. T. Yosua and S. L. Brooks, "The appearance of mental foramina on panoramic radiographs. I. Evaluation of patients," Oral Surg. Oral Med. Oral Pathol., vol. 68, no. 3, pp. 360-364, Sep. 1989. DOI: 10.1016/0030-4220(89)90224-7

8. P. S. Igbigbi and S. Lebona, "The position and dimensions of the mental foramen in adult Malawian mandibles," West African Journal of Medicine, vol. 24, no. 3, pp. 184-189, 2005.

DOI: 10.4314 /wajm.v24i3.28195

PMid: 16276691

9. R. Singh and A. K. Srivastav, "Study of position, shape, size and incidence of mental foramen and accessory mental foramen in Indian adult human skulls," Int. $J$. Morphol., vol. 28, no. 4, pp. 1141-1146, Dec. 2010. DOI: 10.4067/So717-95022010000400025

10. W. C. Ngeow, "Is there a "safety zone" in the mandibular premolar region where damage to the mental nerve can be avoided if periapical extrusion occurs?” J. Can. Dent. Assoc., vol. 76, pp. a61, 2010. PMid: 20579448

11. M. H. Al-Shayyab, F. Alsoleihat, N. S. Dar-Oden, S. Ryalat, Z. H. Baqain, "The mental foramen I: radiographic study of the anterior-posterior position and shape in Iraqi population," Int. J. Morphol., vol. 33, no. 1, pp. 149-157, Mar. 2015. DOI: $10.4067 /$ So717-95022015000100024

12. M. Babshet, R. Sandeep, K. Burde, K. Nandimath, "Evaluation of the position of mental foramen and its correlation with age in selected Indian population using digital panoramic radiograph," International Journal of Dental Sciences and Research, vol. 3, no. 4, pp. 8791, 2015. DOI: 10.12691/ijdsr-3-4-2

13. A. Chkoura, W. E. Wady, "Position of the mental foramen in Moroccan population: A radiographic 
study," Imaging Sci. Dent., vol. 43, no. 2, pp. 71-75, Jun. 2013.

DOI: $10.5624 /$ isd.2013.43.2.71

PMid: 23807929

PMCid: PMC3691376

14. T. Hasan, "Characteristics of the mental foramen in different populations," The Internet Journal of Biological Anthropology, vol. 4, no. 2, 2010.

Retrieved from: http://ispub.com/IJBA/4/2/6914

Retrieved on: Dec. 15, 2015.

15. A. Santini, I. A. Alayan. "A comparative anthropometric study of the position of the mental foramen in three populations," Br. Dent. J., vol. 212, p. E7, 2012.

DOI: $10.1038 /$ sj.bdj.2012.143

PMid: 22349415

16. N. M. Al Jasser and A. L. Nwoku, "Radiographic study of the mental foramen in a selected Saudi population," Dentomaxillofac. Rad., vol. 27, pp. 341-343, 1998.

DOI: $10.1038 /$ sj.dmfr.4600388

PMid: 10895632
17. H. K. Berberoglu, G. Ak, A. Brkić, E. Eyupoglu, "An endodontic overfilling occupied the foramen mentale- A case report," Int. Journal of Contemporary Dentistry, vol. 2, pp. 109-112, 2011.

18. G. Greenstein and D. Tarnow, "The Mental Foramen and Nerve: Clinical and Anatomical Factors Related to Dental Implant Placement: A Literature Review," $J$. Periodontol., vol. 77, no. 12, pp. 1933-1943, Dec. 2006. DOI: 10.1902/jop.2006.060197

PMid: 17209776

19. C. Bou Serhal, R. Jacobs, L. Flygare, M. Quirynen and D. van Steenberghe, "Perioperative validation of localisation of the mental foramen," Dentomaxillofac. Rad., vol. 31, no. 1, pp. 39-43, 2002.

DOI: $10.1038 /$ sj.dmfr.4600662

20. D. Denio, M. Torabinejad, and L. K. Bakland, "Anatomical relationship of the mandibular canal to its surrounding structures in mature mandibles," $J$. Endod., vol. 18, no. 4, pp. 161-165, Apr. 1992.

DOI: 10.1016/Soo99-2399(06)81411-1 